)

||||||||||||

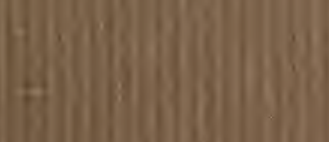

11.10 



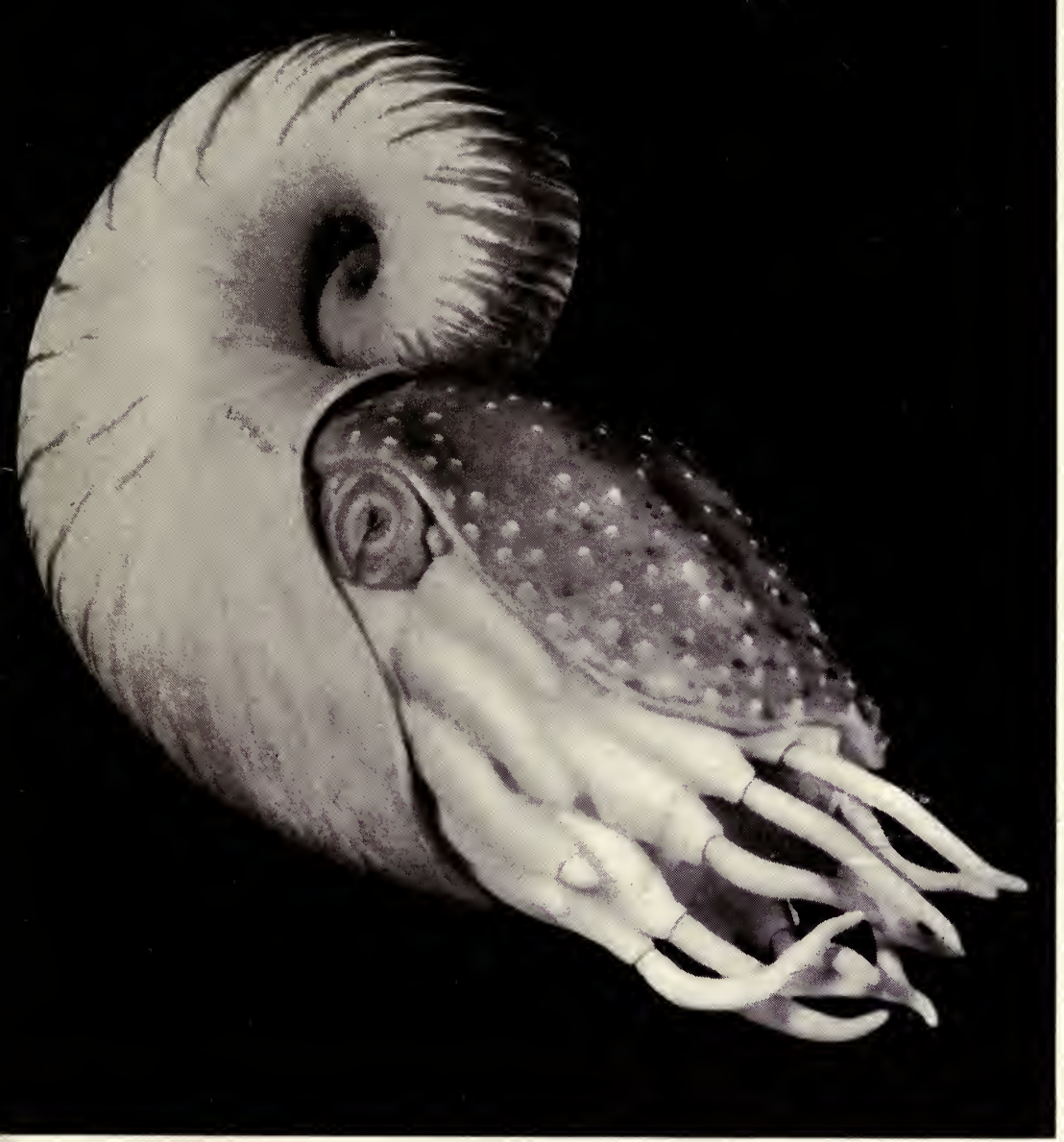

\section{Common Fossils of Western New York} CAROL A. HEUBUSCH 
EARTH

SCIENCES

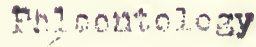

GIFT 


\title{
Common Fossils of Western New York
}

\author{
Carol A. Heubusch
}

Geologist, Buffalo Museum of Science

\section{Introduction}

There are many people who find a fossil and want to know something about it. This article has been prepared to aid these amateur collectors. Descriptions are limited to the common invertebrate fossils of Western New York although some primitive plants and fishes are found. Many kinds of fossils are not discussed for various reasons: few or no representatives are present locally; there is difficulty in recognizing and identifying some groups; space is lacking to provide necessary detailed descriptions of the numerous classifications.

\section{What is a Fossil?}

A fossil is some evidence of the existence of a plant or animal which is found preserved in the rocks. To insure preservation, it is necessary that organisms be embedded soon after death in some protective material. Hard parts must be present since soft parts of organisms are rarely preserved. Some sort of alteration of the resistant parts usually occurs, either mineral infiltration of pore spaces or substitution of the original material by mineral matter. The resulting composition of the fossil is often calcium carbonate, the same substance of which the hard parts may be originally composed. Some fossils are composed of silica while others are of chitin, a complex organic substance. Fossils are sometimes preserved as black carbonaceous films on rock.

Besides the actual remains of animals and plants, any evidences of their former existence are counted among the fossils. Objects indicating the former presence of organisms include casts and molds, trails, tracks, imprints, and burrows.

Fossils are often not perfectly preserved. They may be crushed or distorted and they are frequently fragmentary. Many fossils can be identified from fragments.

Fossils are found in almost all the sedimentary rocks of Western New York. The essentially flat-lying layered rocks are composed of sediments once deposited in warm shallow seas covering this area. This occurred mainly during the geologic times of the earth's history called the Devonian and Silurian periods over 300 million years ago. There was a great abundance and variety of life in these seas. A small percentage of the animals was preserved in the soft sediments. The sediments consolidated forming rock, the finer grained forming shale and the coarser grained, sandstone. Calcium carbonate was precipitated from the sea water; it settled to the bottom and became limestone.

Irregularly rounded rocks of various sizes are often mistaken for fossils. These rocks may be concretions which have been formed inorganically by the collection of mineral matter around some nucleus. They may resemble animal bones. Rocks divided into segments by cracks which have been filled with a different rock may be mistaken for fossil turtle shells. 


\section{What are the Characteristic Fossil Groups?}

\section{Porifera}

The sponges or Porifera comprise the simplest group of multicelled animals. They typically are attached forms of marine environment. Sponges are of greatly varied shape, being globular, cylindrical, conical, or irregular.

The soft body of a sponge is generally supported by an internal skeleton composed of organic fibers or spicules. The most commonly found fossil representatives of sponges in Western New York are spicules. Spicules show considerable range in shape, size, composition, and structure. They consist fundamentally of simple spines or of spines radiating from a point. Size of these spicules is small, averaging less than one-fourth of an inch in length.

In many extinct sponges the spicules were the most prominent hard parts. They frequently became thickened and united to form a solid trellis or framework which retained the form of the sponge during fossilization. Fossil sponges include isolated spicules of calcium carbonate or silica, fragmentary or whole skeletons, and, rarely, the distorted outlines of complete bodies. Sponge fossils are usually poorly preserved and difficult to recognize.

\section{Coelenterates}

Corals are bottom-dwelling marine coelenterates which have an extensive fossil record and are still abundant in warm shallow seas. These animals secrete calcium carbonate skeletons about the sides and base of their barrel-shaped bodies. This encases the lower part of the coral in a conical or cylindrical tube or forms a flattish basal expansion. Radiating calcareous vertical partitions called septa are built by infolded parts of the body covering. These partitions help to strengthen the animal. The animal lives in the depression at the top of the coral. As it grows, the skeleton is built upward; earlier parts are abandoned, and new supporting structures are built beneath itself. These horizontal plates are termed tabulae and together with septa are often significant features of fossil corals.

Corals may live singly but many kinds are of a colonial nature, hundreds of individuals being attached to each other by their outer skeletal walls. The corals that form isolated fossils are called cup corals or horn corals. They range from almost microscopic in size to two feet or more in length and over twenty inches in width. These conical-shaped fossils often display the radiating septa at the top. The outer surface of the walls varies. It may be wrinkled and irregular with encircling growth lines, or may show vertical septa when the outer wall is worn away.

A cup coral common in Western New York is Heliophyllum halli. It averages three to four inches in length. The major radiating septa extend
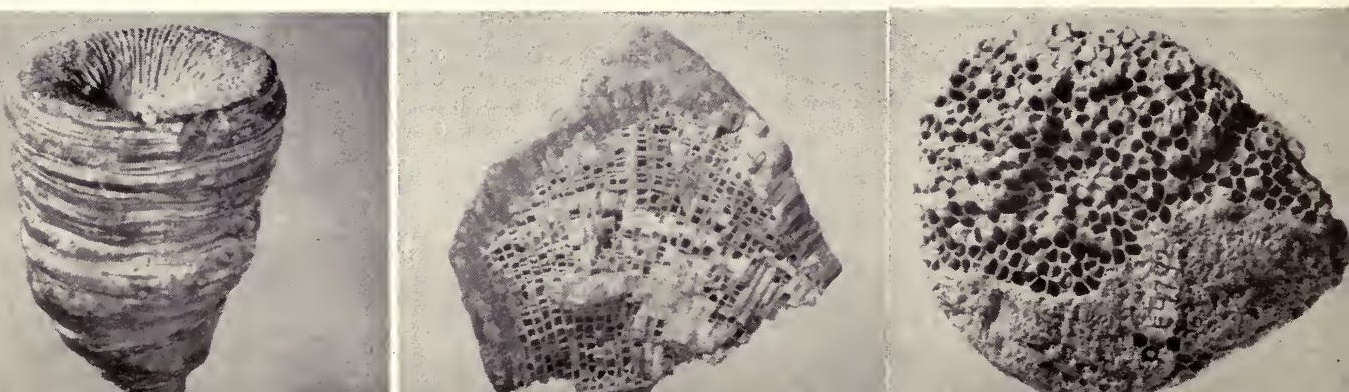
to the center of the coral like the spokes of a wheel and are strengthened by small crossbars. The outer surface of the coral is strongly wrinkled.

In colonial forms the skeleton may be branching or closely packed and massive. Colonial corals were very numerous in the Devonian and Silurian seas once covering Western New York. Favosites is an abundantly found fossil whose massive colony may be a few feet in diameter. The colony is made up of numerous prismatic shaped individual tubes a fraction of an inch in diameter. They have no vertical septa but characteristically possess many horizontal partitions or tabulae. The vertical walls of the individual animals are perforated by small pores. Favosites is often called honeycomb coral.

Pleurodictyum is a colonial coral of a depressed and disc-like shape. A concentrically wrinkled covering is found over the lower surface. The individual corals average one-fourth of an inch or less in diameter and are prismatic and funnel-shaped. The colony averages a few inches in diameter. Pleurodictyum is sometimes mistaken for a fossil turtle shell because of its convex mosaic-like surface.

\section{Bryozoans}

Most bryozoans are tiny, colonial marine animals. The calcareous skeletons formed by the colony of animals are often preserved as fossils. Some fossils consist of a simple chainlike series of tubes usually found encrusting foreign surfaces such as brachiopod shells. Others form thin leaflike expansions, rounded branches, massive bodies, or lacy fans. The tiny holes seen perforating the fossils are the openings where each animal of the colony lived.

Bryozoans are common local fossils; they are found in a great variety of shapes and sizes. One of the commonest Western New York bryozoan fossils is Fenestrellina (often called Fenestella) which is a fan or funnelshaped, lacelike colony. The individual animals lived in the almost microscopic double row of holes along the radiating branches.

\section{Brachiopods}

Brachiopods are common fossils of Western New York because they were among the dominant forms of the ancient life which existed here and possessed the necessary hard parts to be preserved as fossils. The hard parts consist of an external shell of two parts called valves. In this respect they bear a superficial resemblance to clams. However, the valves of brachiopods differ from those of clams because they are of unequal size and shape. If the brachiopod were to be cut so that two equal valves resulted, the cut would pass through the middle of each valve, while in a clam it would pass between the valves.
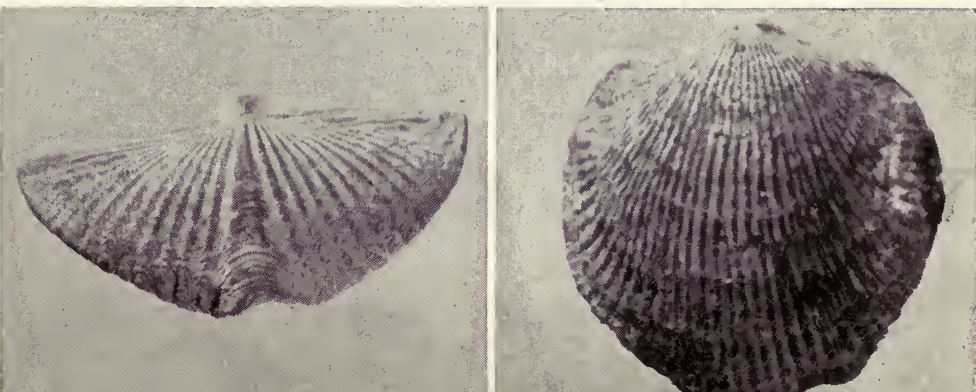
Brachiopod fossils vary greatly in size, from less than one-fourth of an inch to several inches. They are of calcium carbonate or chitinophosphatic composition. Many of the shells have variously shaped structures or platforms which supported soft parts of the animal; they are found on the inside of the valves.

Shells of brachiopods are characterized by a wide diversity of appearance. Some are circular or elliptical in outline while others are irregular. Some shells have two very convex valves; some have one convex and one almost flat valve; others may have one convex and one concave valve.

Where the halves of the shell are joined, one valve typically has a pointed beak. At this end of the fossil is the hinge line, an area which varies greatly in different kinds of brachiopods. When the hinge line is short, the shell shape is pointed at that end.

A shell with a wide hinge line may possess greater width than length. An example is Mucrospirifer mucronatus. This species is characterized by lines radiating from the center of the hinge line and by a prominent center fold in one valve and corresponding depression in the other.

Some brachiopod shells are smooth; others, such as the common Atrypa reticularis, display prominent ridges and grooves radiating out from the hinge of the shells plus growth lines concentrically arranged.

\section{Gastropods}

\section{Mollusks}

Snails, or gastropods, are mollusks possessing a single shell which is usually coiled into a spiral, although it may be conical or saucer-shaped. The animal lives in the entire shell which is not partitioned into chambers. Growth lines are often present encircling the shell. Ornamentation of various types may occur including ridges, folds, and spines.

Although gastropods were abundant in the ancient seas the gastropod shells were quite easily destroyed because they were mainly composed of a relatively soluble mineral called aragonite. Many gastropod fossils may be merely fillings of the shell interior. They are internal molds which do not indicate the outer form of the shells and therefore are difficult to identify.

Some gastropod fossils may be recognized because of characteristic coiled or conical forms. Others, such as Platyceras, possess horn-shaped shells of irregular growth reflecting irregularities in the object to which the shell was fixed during life.

\section{Pelecypods}

Clams, or pelecypods, have calcium carbonate shells composed of two valves typically equal in size and shape, each half being the mirror image of the other. Each valve is often asymmetrical in outline. These features are the most evident means of differentiating pelecypods from the more commonly found brachiopod fossils which also possess two valves but of unequal size and shape.

Concentrically arranged growth lines are commonly present as are various types of ornamentation such as radiating ribs. Fossils may consist 
of the shell or of internal fillings or external molds. They generally range in size from a fraction of an inch to a few inches in length and width.

\section{Cephalopods}

Cephalopods are among the most highly developed mollusks. Squids, octopuses, cuttlefish, and the pearly nautilus are living representatives of this class which are abundantly represented as fossils. The calcium carbonate shell possessed by ancient forms has essentially the form of a slender cone which may be straight, curved, or coiled. Whether loosely to tightly coiled, it is almost always in a flat spiral.

The animal occupied only the end portion of the fossil shell. It sealed this "living chamber" off from the rest of the shell by transverse partitions called septa. The line of junction of the septa with the inner surface of the shell wall is called the suture. In most fossil cephalopods the outer shell has been eroded away, exposing the characteristic kinds of sutures. These suture lines and the presence of a small tube running through the septa connecting the chambers are distinguishing features of cephalopods.

Straight and coiled shelled cephalopod fossils are found in the shales and limestones of Western New York. The cover portrays a restoration of the nautiloid cephalopod Nephriticeras. Its shell can be found locally.

\section{Annelids}

Annelid worms are represented by fossils of various forms including tooth-bearing jaw parts, trails, castings, and tubes. The worm jaws, called scolecodonts, show considerable range in shape, size, structure, and number. These microscopic or near-microscopic fossils are usually composed of chitin and are recognized by their black, glossy, opaque appearance.

Fossil worm tubes are minute straight or coiled snail-like forms which can be found cemented to the surface of other fossils. The tubes are often ornamented with ridges, spines, and nodes.

Fossil worm borings or trails are occasionally found but are generally difficult to recognize. Arthrophycus, a fossil found in the rocks of the Niagara Gorge, is believed by some paleontologists to be worm tubes; others consider it a primitive plant.

\section{Conodonts}

Conodonts are minute, toothlike, transparent, or translucent fossils. Conodonts can be distiguished from fossil worm jaws or scolecodonts by their smaller size, calcium phosphate composition, translucent nature, and pale amber to dark brown color.

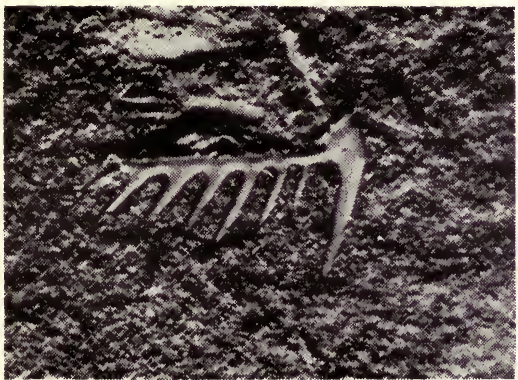

Conodont

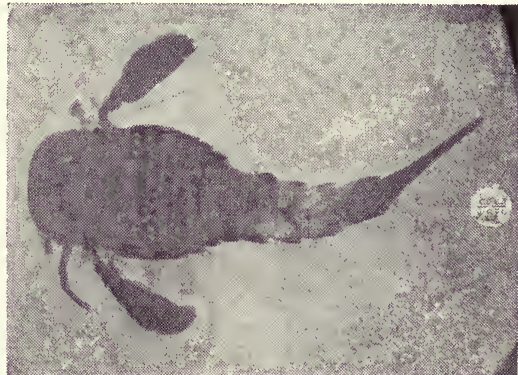

EURYPTERID-Eurypterus lacustris 
These fossils are of unknown origin. Because of great diversity in size and shape, the conodonts have at various times been called worm teeth, fish teeth, parts of arthropods, gastropods, and cephalopods.

\section{Eurypterids}

\section{Arthropods}

Eurypterids are extinct representatives of a group of animals which include the spiders and scorpions. Up to nine feet in length, these arthropods were scorpion-like in appearance. They possessed a thin, chitinous, segmented shell and a tail which was either long and pointed or flat. Jointed legs are found fossilized. Many eurypterids had large compound eyes on the dorsal (upper) surface.

Western New York is very well known for the eurypterids obtained from its Silurian rocks. However, it is no longer possible to collect specimens because the principal collecting locality, which was in the quarry behind Bennett High School, is no longer accessible. Eurypterus lacustris is an eurypterid known from specimens found locally. It averaged about a foot in length and is characterized by large eyes and a pointed tail.

The seal of the Buffalo Society of Natural Sciences depicts an eurypterid.

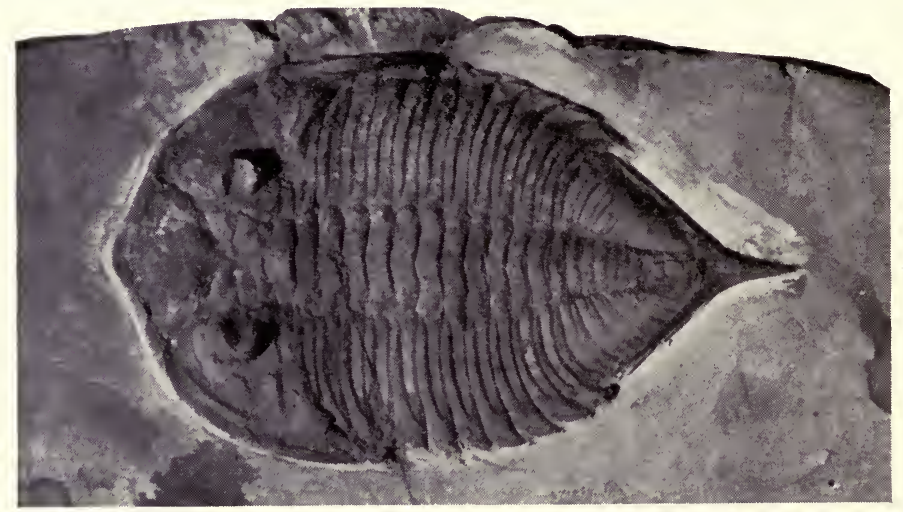

Trilobite-Dalmanites

\section{Trilobites}

Trilobites are an extinct group of insect-like animals which have left abundant and varied fossils. Most are less than two inches in length although they vary from less than one fourth of an inch to thirty inches.

The animals were well protected on the dorsal surface by a hard shield which was differentiated into three parts: a head (cephalon) sometimes possessing large compound eyes; a thorax often of numerous jointed segments; and a spiny or rounded tail (pygidium). The body is characterized by an elevated ridge longitudinally along the center.

Trilobites molted as they grew, casting off their old exoskeletons much the same as insects do today. Many fossils are the castoff immature shells. 
While the animals possessed a hard dorsal covering, their lower surface was not similarly protected. To protect themselves from enemies the trilobites curled up into balls. Fossils may be found of curled up trilobites.

Trilobite fossils are often fragmentary because the trilobite shell is so differentiated and the sections easily separated. A commonly found trilobite in the rocks of Western New York is Phacops rana. It is characterized by large popping eyes and an oval-shaped body of many segments Dalmanites is a trilobite with a thorax of eleven segments and a tail which is often large and pointed.

\section{Ostracodes}

Ostracodes are usually microscopic or almost microscopic crustaceans, the same class of animals that includes lobsters and crabs. The oval or bean-shaped shells of ostracods are composed of two valves hinged at the top. The shells may be smooth and rounded or marked by various structures such as lobes, pits, spines, or nodes.

Fossil ostracodes are common in some of the rock formations of Western New York but may be difficult to find because of their small size.

\section{Echinoderms}

Echinoderms include animals well known today, such as the star-fishes, as well as forms known only as fossils. The echinoderm shell is in the form of calcium carbonate plates which form mosaic patterns covering the body. Many fossil echinoderms were attached to some foreign object or to the sea bottom by a flexible jointed stem.

\section{Cystoids}

Cystoids, the most primitive echinoderms, possess a body of irregularly arranged plates which result in a fossil of saclike indefinite form. The body plates in most cystoids are five-sided or polygonal in shape and are perforated by pores or fissures.

A cystoid found in Western New York is the oval shaped Caryocrinites ornatus. It is characterized by pores radiating from the center of the individual plates. These pores form rhombic-shaped designs covering the fossil.

\section{Blastoids}

Blastoids are extinct echinoderms with a symmetrical, often bud-like, body usually less than an inch in diameter. Their bodies are encased in shells composed of thirteen principal plates firmly knit in definite positions. There are five food grooves running downward from the top of the blastoid.

A representative Western New York blastoid, Nucleocrinus, is of about the size and shape of a small olive. The five food grooves are very narrow in this particular species.

TRILOBITE-Phacops rana

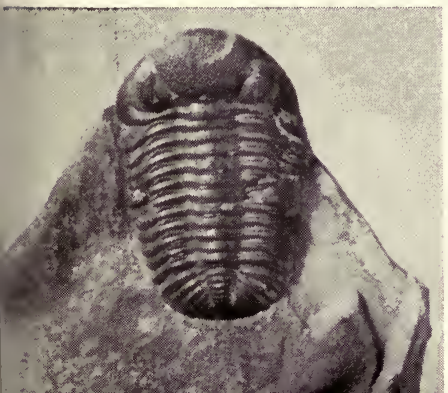

BLAstoID-Nucleocrinus

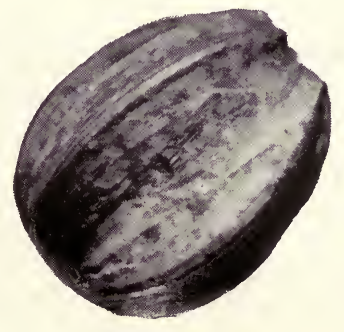

Grinom Stems

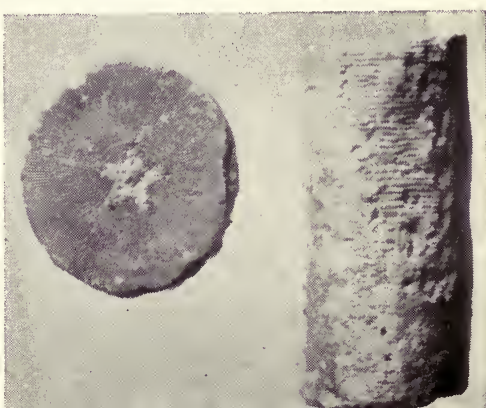




\title{
Crinoids
}

The crinoids, sometimes called sea-lilies, are animals of a plant-like appearance. Their globular or cup-shaped bodies with radiating jointed arms are generally supported by a stem or stalk. Their total length may be from a fraction of an inch to over sixty feet. Plates cover the body in a symmetrical fashion, usually in arrangements of five.

The crinoid stem consists of numerous button-like discs stacked in a column. Through the center of the stem is typically found a rounded or a star-like opening. Crinoids lived in great numbers in the shallow Devonian and Silurian seas. Very rarely is the whole animal preserved; upon the death of the animal its calcium carbonate plates fell apart. Disc-shaped sections of crinoid stems are among the commonest fossils in many local rocks, at places making up a large percentage of the rock itself.

\section{Graptolites}

Graptolites are extinct, colonial organisms which usually appear fossilized as flattened films of carbon on rocks. They possessed a protecting and supporting skeleton; the individual animals lived in cups or pits along the chitinous stalk. In some forms the stem was attached to a round float and in others two, three, or four stems might be attached together. Most graptolites floated free in the oceans and were scattered throughout the world.

During fossilization the skeletons became carbonized so that they resemble black shiny lines with irregular edges. Inocaulis is a graptolite which can be found in the rocks of Western New York.

\section{References}

Goldring, W. F. 1950. Handbook of Paleontology for Beginners and Amateurs: Part 1, The Fossils. Second Edition. New York State Museum Handbook 9.

Grabau, A. W. 1899. The Paleontology of Eighteen Mile Creek and the Lake Shore Sections of Erie County, New York. Buffalo Society of Natural Sciences Scientific Bulletin 6.

Grabau, A. W. 1901. Guide to the Geology and Paleontology of Niagara Falls and Vicinity. New York State Museum Bulletin 45. pp. 130-252.

Moore, R. C. (ed.) 1955-. Treatise on Invertebrate Paleontology. University of Kansas Press and Geology Society of America. Parts in process of publication.

Shimer, W. H. and Shrock, R. R. 1944. Index Fossils of North America. New York: John Wiley and Sons, Inc.

Shrock, R. R. and Twenhofel, W. H. 1953. Principles of Invertebrate Paleontology. Second Edition. New York: McGraw-Hill, Inc.

\author{
Reprinted from HOBbIES, the Magazine \\ of The Buffalo Museum of Science \\ Buffalo, New York
}

VoL. 37, No. 4 



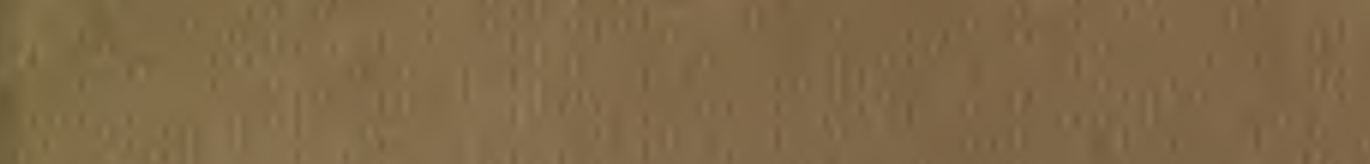

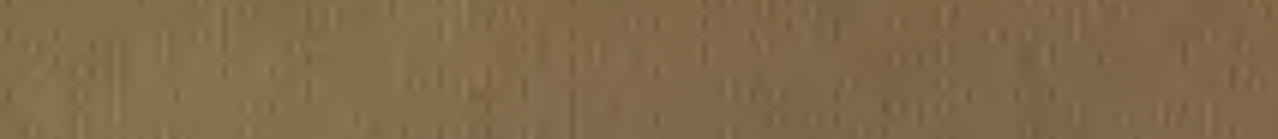

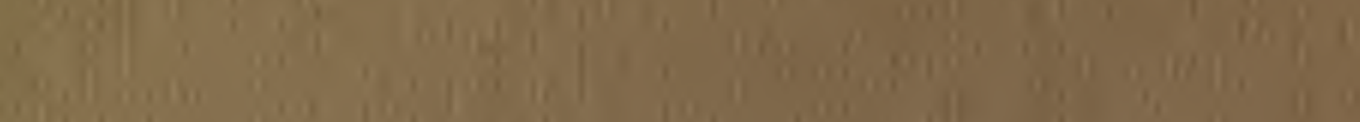

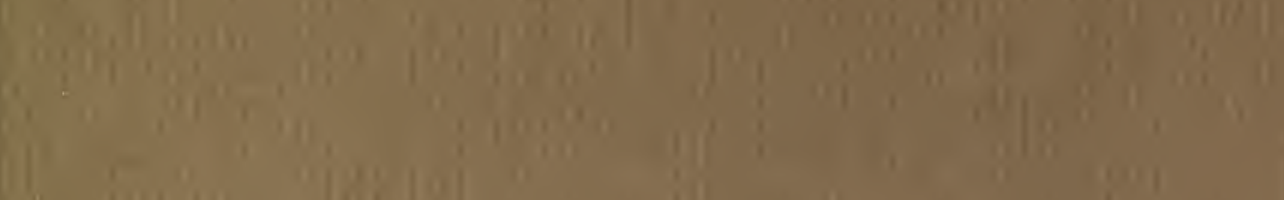
It

$\left(\begin{array}{ll}4 \\ 4\end{array}\right.$

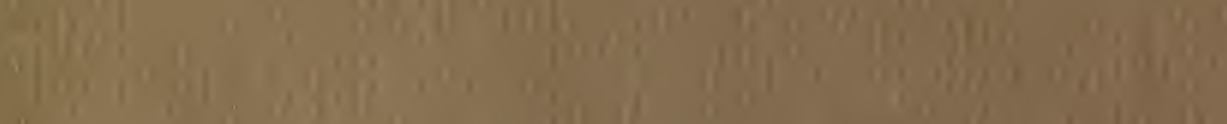

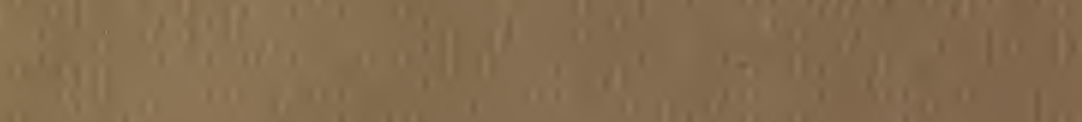

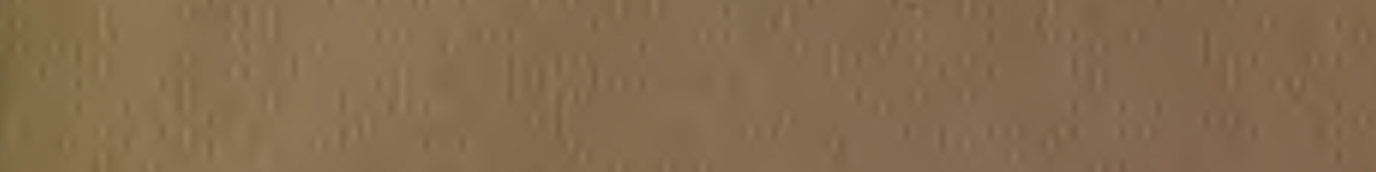

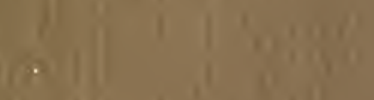

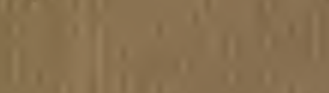
$\left.\lim _{i=1}\right|_{i=1}$
$\frac{n}{3}$

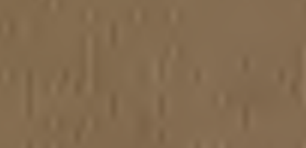

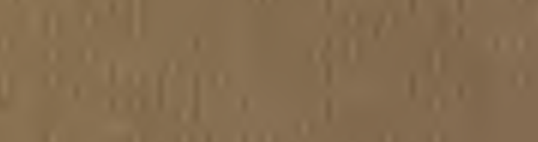
$x^{x} \operatorname{lin}^{x} x$

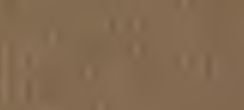

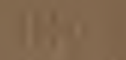

1,1 10

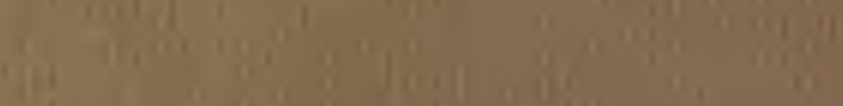

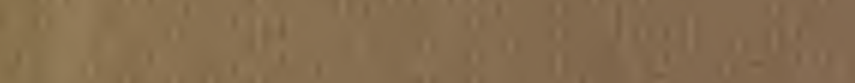

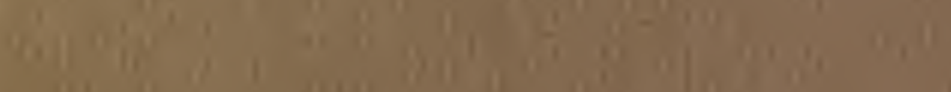

$(1)$

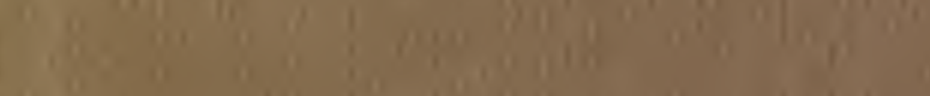

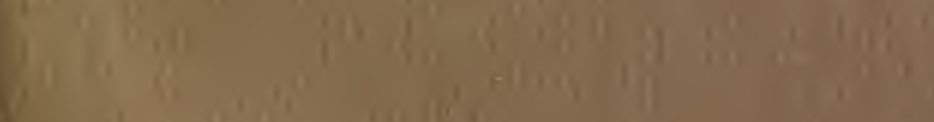

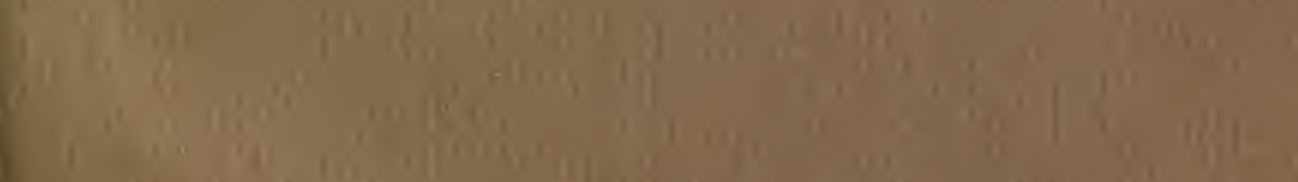

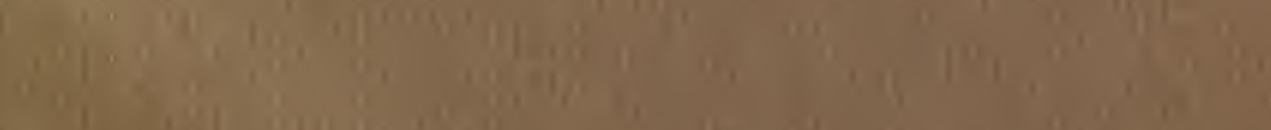

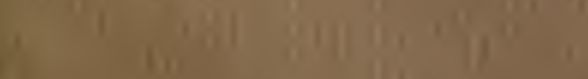

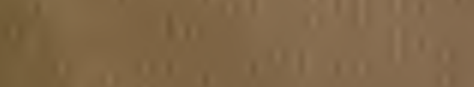

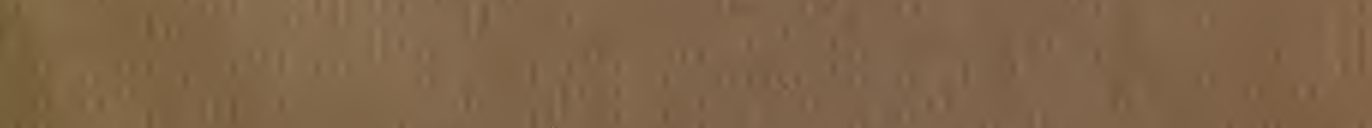

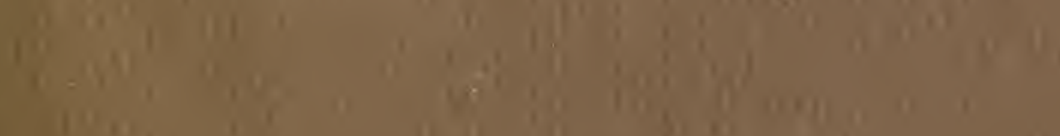

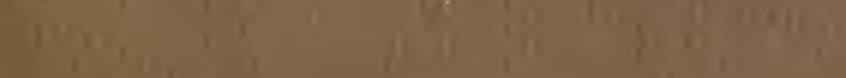

.

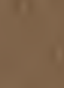

(1) $|1|$ 


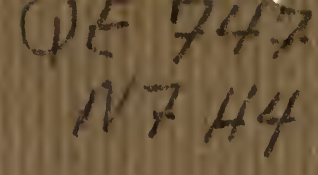

\section{DAY USE \\ RETURN TO DESK FROM WHICH BORROWED EARTH SCIENCES LIBRARY}

This book is due on the last date stamped below, or on the date to which renewed.

Renewed books are subject to immediate recall.

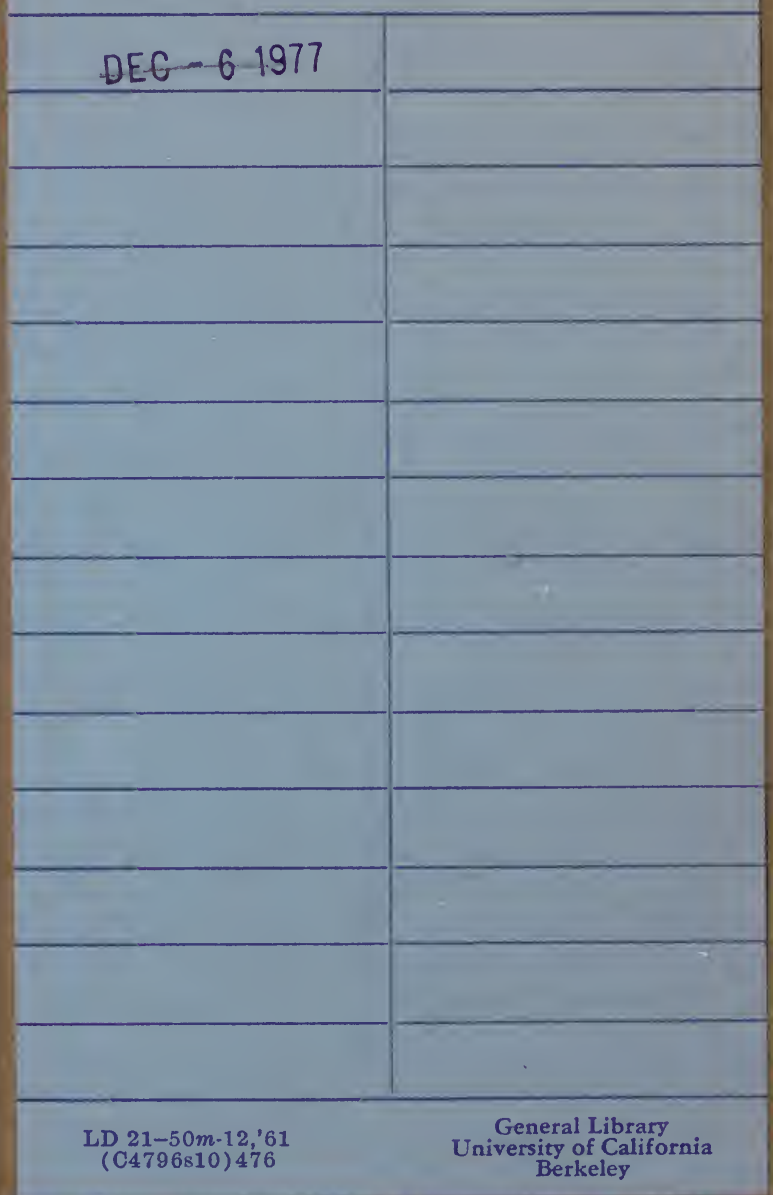




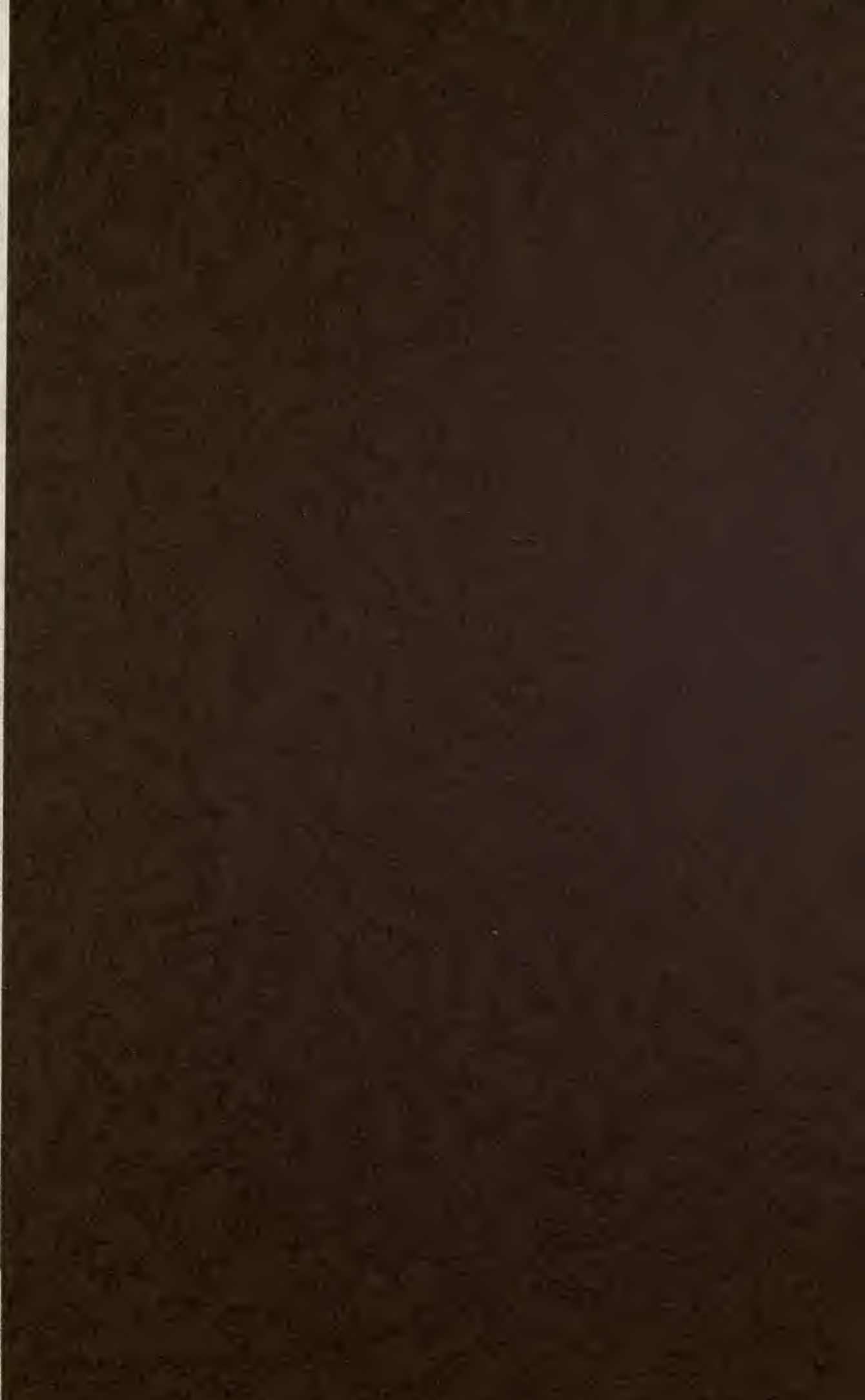




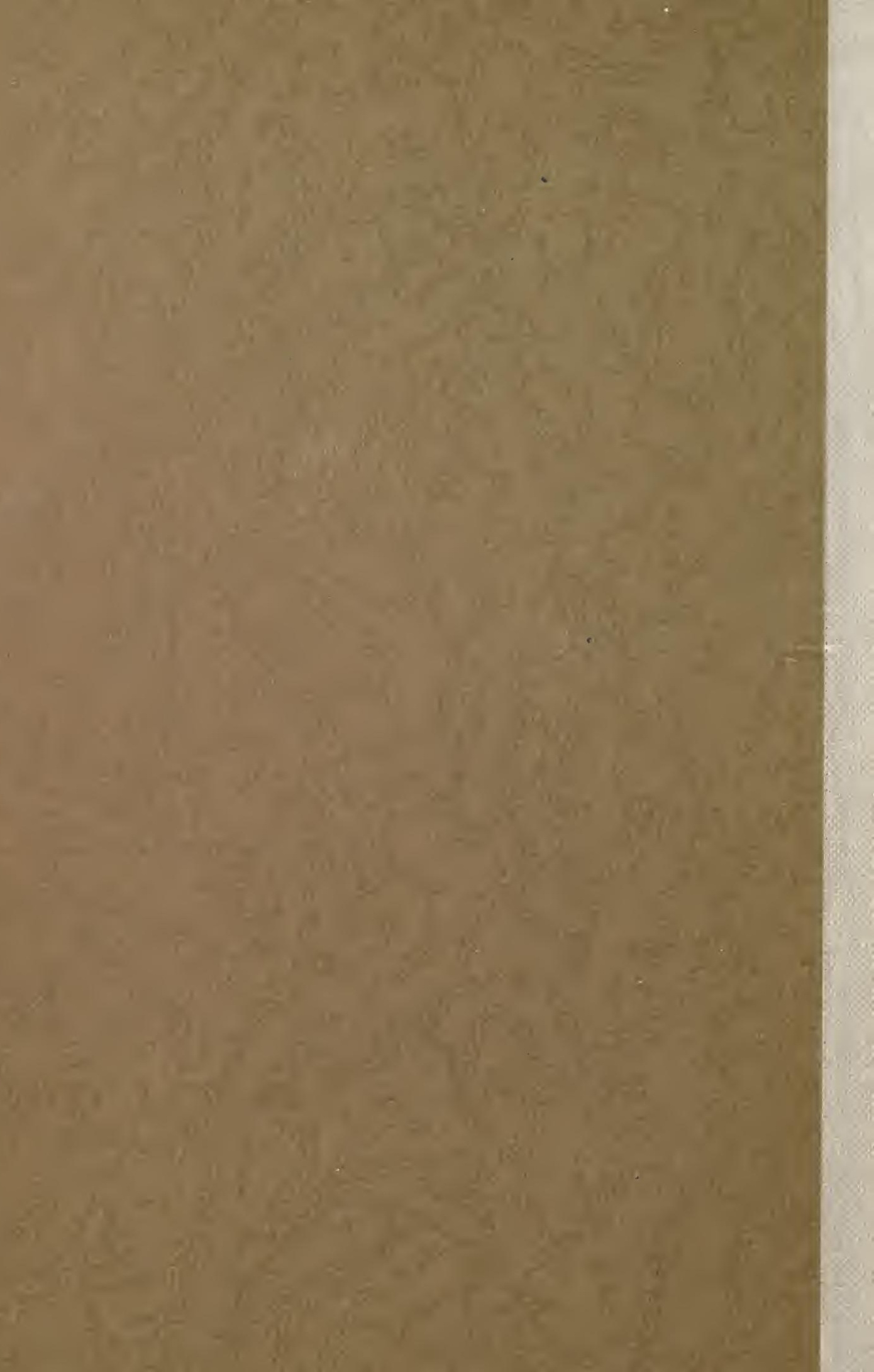

